\title{
Gentamicin in the treatment of gonorrhoea in females
}

\author{
W. BOWIE, A. R. RONALD, W. KRYWULAK, C. Y. CATES, AND P. BOUTROS \\ From the Departments of Medical Microbiology and Obstetrics and Gynecology, University of Manitoba, \\ Canada
}

The increasing resistance of Neisseria gonorrhoeae to many antimicrobial agents demands a continual search for alternative drugs for its treatment. As more resistant strains emerge, it is conceivable that the required dose of penicillin, even with probenecid, will become too large to be acceptable. The aminoglycosides are among the potential alternatives. Kanamycin has already been shown to be efficacious in investigations by Wilkinson, Race, and Curtis (1967), Hooton and Nicol (1967), and Fischnaller, Pedersen, Ronald, Bonin, and Tronca (1968). Spectinomycin hydrochloride is also proving to be an acceptable alternative to penicillin. Neisseria gonorrhoeae has been shown by Finland (1969), Waitz and Weinstein (1969), and Phillips, Rimmer, Ridley, Lynn, and Warren (1970) to be susceptible in vitro to gentamicin at concentrations that are readily achieved in vivo. Felarca, Laqui, and Ibarra (1971), Siboulet (1972), and Hantschke, Strauss, Linzenmeier, Gahlen, and Heller (1973) have used gentamicin to treat gonorrhoea. In the present study, gentamicin was used successfully to treat females with gonococcal infection.

\section{Material and methods}

Women presenting at the Venereal Disease Clinic at the Winnipeg General Hospital with a history suggestive of gonorrhoea, contact with a known case of gonorrhoea, or a known positive cervical culture, had a cervical swab taken for smear and culture, and blood was taken for a VDRL. They were then given $240 \mathrm{mg}$. gentamicin intramuscularly as a single injection of $6 \mathrm{ml}$. into the upper outer quadrant of one buttock. No rectal or pharyngeal cultures were taken. Patients were then requested to return for follow-up cultures at $48 \mathrm{hrs}, 5$ days, and 12

Received for publication September 17, 1973

Address for reprints: Dr. A. Ronald, Infectious Diseases, Health Sciences Centre, 700 William Avenue, Winnipeg, Manitoba R3E 0Z3, Canada

*Director, Venereal Disease Control, Department of Health and Social Development, Province of Manitoba, Canada days. At these times, patients were questioned about sideeffects, symptoms, and sexual activity.

Cervical swabs were inoculated directly onto a split Thayer-Martin chocolate agar plate and incubated at $35^{\circ} \mathrm{C}$. in 5 to 10 per cent. $\mathrm{CO}_{2}$ for $48 \mathrm{hrs}$; the ThayerMartin chocolate agar plate was then examined for oxidase-positive colonies containing Gram-negative diplococci. Such colonies were further identified by the fluorescent antibody technique and by sugar fermentations. 42 isolates were tested for sensitivity to penicillin, streptomycin, kanamycin, tobramycin, and gentamicin using Mueller-Hinton agar (Baltimore Biological Laboratory) with added Isovitalex to give final concentrations in a $\log _{2}$ dilution series. Penicillin concentrations ranged from 0.005 to $100 \mathrm{i}$ i.u./ml., streptomycin from 0.04 to $100 \mu \mathrm{g}$./ $\mathrm{ml}$., kanamycin from 0.04 to $200 \mu \mathrm{g}$. $/ \mathrm{ml}$., tobramycin from 0.004 to $50 \mu \mathrm{g} / \mathrm{ml}$., and gentamicin from 0.04 to $25 \mu \mathrm{g}$. $/ \mathrm{ml}$. The tests were performed with a Steers inoculum replicator, approximately $0.002 \mathrm{ml}$. being transferred as a spot inoculum. The plates were incubated in a $\mathrm{CO}_{2}$ incubator at $35^{\circ} \mathrm{C}$. and read after $24 \mathrm{hrs}$. The minimum inhibitory concentration of the antibiotic was accepted as the lowest concentration preventing visible growth.

\section{Results}

55 women with positive cultures were treated. Four did not return for follow-up. Three made only one follow-up visit at $72 \mathrm{hrs}$ and all had negative cultures. All but six of the remaining 48 women returned twice or more and all 48 made at least one visit 4 or more days after treatment.

Four of the 48 with adequate follow-up had a positive culture after treatment:

(1) A 23-year-old woman had had intercourse after treatment with a partner with known gonorrhoea, and was positive on both Day 3 and Day 18 after therapy. After treatment of her consort and re-treatment of the patient with gentamicin, she was negative 15,22 , and 29 days later.

(2) A 21-year-old woman had had intercourse after treatment with a partner with known gonorrhoea and was positive on Day 11, but after further gentamicin and concurrent treatment of her consort she was negative 10 days later. 
(3) A 16-year-old girl known to be promiscuous had a positive culture on Day 5 .

(4) A 16-year-old girl had intercourse between followup visits; she had a negative culture on Day 3 but was positive on Day 9.

Before therapy, a number of women complained of burning on micturition. In all but one patient this cleared up promptly after treatment. Only one patient had a positive VDRL.

There were no significant side-effects. The women tolerated the injection very well with minimal pain.

The results of the sensitivity tests are shown in Fig. 1. Penicillin is not shown, but all strains were sensitive to $0.78 \mathrm{i} . \mathrm{u} . / \mathrm{ml}$. or less. The sensitivity to gentamicin and tobramycin for 42 isolates was similar, with a range of 0.02 to $3.1 \mu \mathrm{g} . / \mathrm{ml}$. (median 1.5) for gentamicin, and a range of 0.01 to $6.2 \mu \mathrm{g} . / \mathrm{ml}$. (median 1.5) for tobramycin. 41 isolates were tested with kanamycin; the range was 0.19 to $12.5 \mu \mathrm{g} . / \mathrm{ml}$. (median 6.2). The gonococcal isolates were divided into two populations on the basis of their susceptibility to streptomycin. 22 strains were sensitive to $25 \mu \mathrm{g} / \mathrm{ml}$. or less, while nineteen were inhibited only by $100 \mu \mathrm{g} . / \mathrm{ml}$. or more.

\section{Discussion}

Gentamicin was successful in eradicating Neisseria gonorrhoeae from the cervices of 44 (92 per cent.) of the 48 women who had an adequate follow-up. Of the four who at some time in the follow-up period had positive cultures, at least two (Cases 1 and 2) were almost certainly re-infected; they responded to gentamicin therapy when their consorts were treated concurrently. Patients 3 and 4 may have been treatment failures, although re-infection in both was possible. The finding of a negative culture on the third post-treatment day and a positive culture on the ninth day is probably more suggestive of reinfection than relapse. Johnson, Kvale, Afable, Stewart, Halverson, and Holmes (1970) found that 21 of 22 failures were detected in the first 3 days.

Rectal cultures were not taken in this study. This would not obscure the diagnosis as only known cases are reported here, but failures can be missed if rectal cultures are not taken. Schroeter and Reynolds (1972) found that, in 908 women treated by a variety of regimens, treatment failed in 96 (10.6 per cent.), and 29 (30 per cent.) of these failures were detected only by rectal culture. They also found that patients with rectal, or rectal and cervical, gonorrhoea had higher failure rates than patients with cervical gonorrhoea alone.

Kanamycin sulphate may show an even greater discrepancy in the treatment of rectal gonorrhoea. Fluker and Hewitt (1970) found that 15.5 per cent. of ninety males with rectal gonorrhoea treated with $2 \mathrm{~g}$. kanamycin failed to respond. On this regimen, only 3 per cent. failed out of 35 with urethral gonorrhoea alone. It is not known whether similar results are found with females or whether these findings apply to gentamicin.

Felarca and others (1971) treated 37 men with gonococcal urethritis with $280 \mathrm{mg}$. intramuscular gentamicin; there were no failures in 34 patients who returned for follow-up. Siboulet (1972) treated 105 men with $240 \mathrm{mg}$. gentamicin; twelve patients (11.4 per cent.) were treatment failures. Hantschke and others (1973) treated 48 females and fourteen males with gentamicin $5 \mathrm{mg}$. $/ \mathrm{kg}$. body weight; this treatment failed in three women and one man (6 per cent.).

Serum levels were not measured in our study. Felarca and others (1971) checked the levels in eight

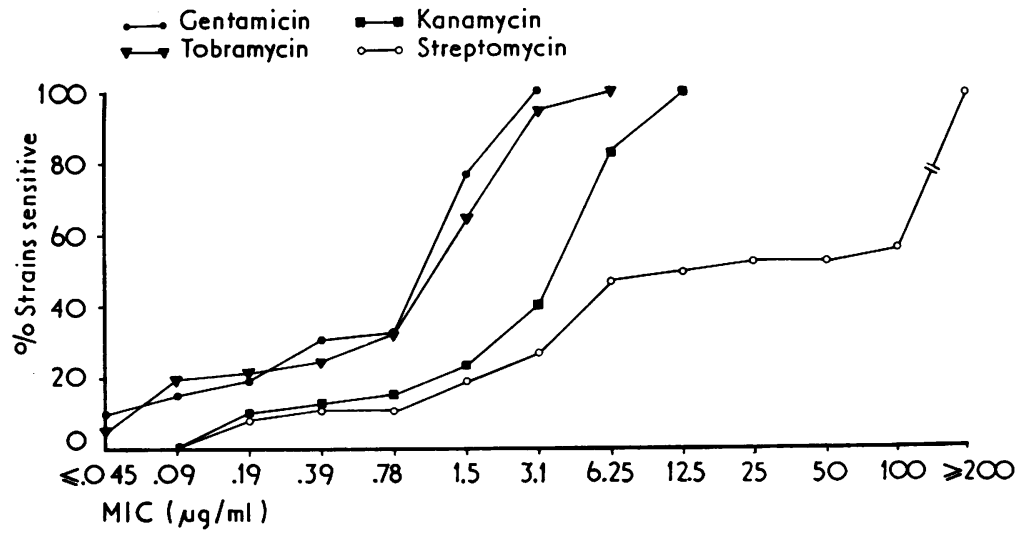

FIG. 1 Sensitivities of N. gonorrhoeae to gentamicin, tobramycin, kanamycin, and streptomycin in Mueller-Hinton agar $(B B L)$ with Isovitalex 


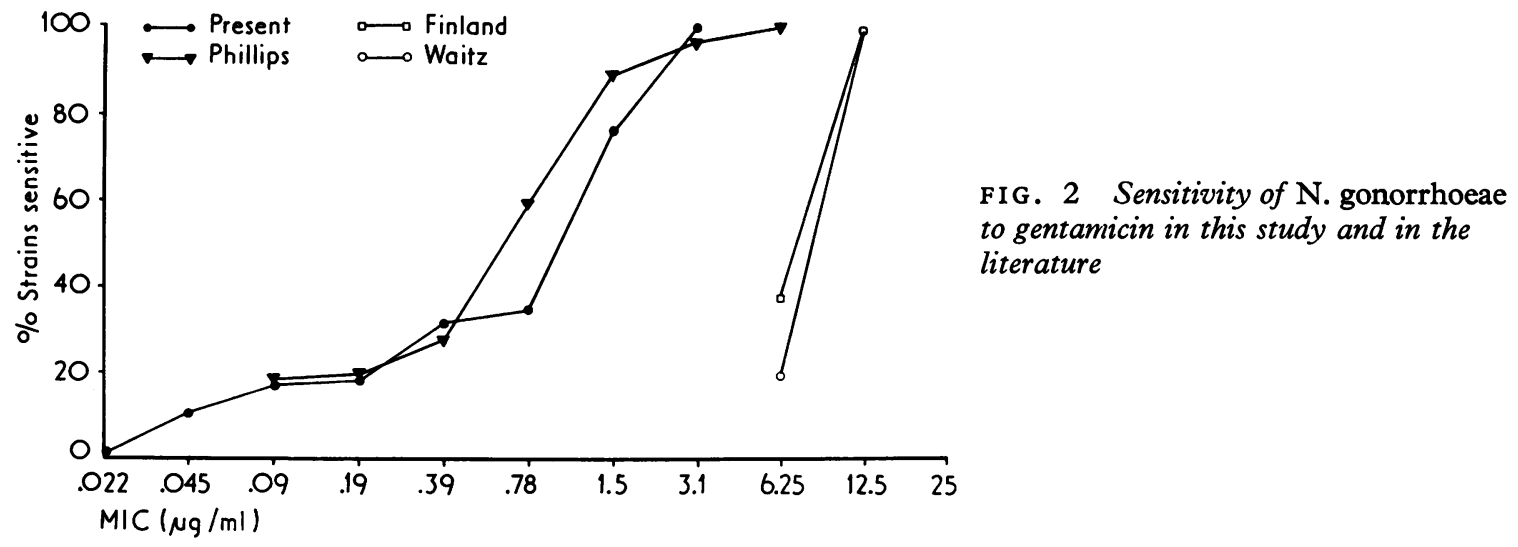

patients; they had received doses of 3.61 to $5 \cdot 71$ $\mathrm{mg} . / \mathrm{kg}$. and attained serum levels of 10.5 to 18.5 $\mu \mathrm{g} . / \mathrm{ml}$. at $1 \mathrm{hr}, 7.25$ to $10.0 \mu \mathrm{g} . / \mathrm{ml}$. at $2 \mathrm{hrs}$, and minimal levels at $12 \mathrm{hrs}$. In five patients receiving $5 \mathrm{mg} . / \mathrm{kg}$. gentamicin, Hantschke and others (1973) noted mean levels of $24 \mu \mathrm{g} . / \mathrm{ml}$. at $1 \mathrm{hr}$ and hardly measurable levels at $12 \mathrm{hrs}$.

The dose range in our study was 3.24 to 4.71 $\mathrm{mg} . / \mathrm{kg}$. with a mean of $3.93 \mathrm{mg} / \mathrm{kg}$. These amounts may be within the range in which ototoxicity could develop, but there is no evidence that a single peak serum level of $10-20 \mu \mathrm{g} . / \mathrm{ml}$. maintained for 1 to 2 hrs is toxic. None of our patients noted otological side-effects. However, careful vestibular and auditory studies of eighth nerve function were not carried out. Hantschke and others (1973) carried out such studies in all their 62 patients but did not find any evidence of ototoxicity.

Few studies have reported the sensitivity of $N$. gonorrhoeae to gentamicin (Fig. 2). Finland (1969) reported on 62 isolates gathered from several laboratories and noted that 37 per cent. were sensitive to $5 \mu \mathrm{g} . / \mathrm{ml}$. and that all were sensitive to $10 \mu \mathrm{g} . / \mathrm{ml}$. Waitz and Weinstein (1969) reported on 49 isolates tested by a tube-dilution method. Some of these isolates may have been included in Finland's study; 20 per cent. were sensitive to $5 \mu \mathrm{g}$. $/ \mathrm{ml}$. and all to $10 \mu \mathrm{g} . / \mathrm{ml}$. Our results on Mueller-Hinton agar with added Isovitalex are very similar to the results of Phillips and others (1970) on Oxoid agar with added lysed horse blood. The median MIC of the 96 isolates tested by Phillips and others (1970) was $0.78 \mu \mathrm{g} . / \mathrm{ml}$., all being inhibited by $6.2 \mu \mathrm{g} . / \mathrm{ml}$. In the present study, the median MIC of the 42 isolates was $1.5 \mu \mathrm{g} . / \mathrm{ml}$., all being inhibited by $3.1 \mu \mathrm{g} . / \mathrm{ml}$.

The sensitivities to kanamycin and streptomycin in vitro are comparable with published data. The sensitivity to tobramycin in vitro was very similar to that of gentamicin.
There are few clinical situations in which gentamicin can be used, penicillin or penicillin derivatives being the agents of choice. In patients with penicillin allergy, spectinomycin is at present the best alternative (Pedersen, Wiesner, Holmes, Johnson, and Turck, 1972). However, gentamicin would be useful in patients with suspected concomitant syphilis as it would not mask the presence of the latter.

Gentamicin fulfils many of the criteria of a useful agent for gonorrhoea, but it is far from ideal. It is expensive and, despite the absence of significant overt side-effects in this study, the possibility of auditory and renal toxicity has not been excluded. It is effective, easily administered, and requires only a single dose. It does not eradicate incubating syphilis (Izzat, Smith, and Knox, 1972) and follow-up studies must include tests for syphilis.

\section{Summary}

Gentamicin, in a dose of $240 \mathrm{mg}$. intramuscularly, was used to treat 55 women with cervical gonorrhoea. Of the 48 who returned for adequate follow-up, 44 were considered to be cured. Of the four patients with recurrences, two were almost certainly reinfected. Thus, the success rate was at least 92 per cent.

\section{References}

Felarca, A. B., LaQui, E. M., IbarRa, L. M. (1971) f. infect. Dis., 124, S287

Finland, M. (1969) Med. Times, 97, no. 12, p. 161

Fischnaller, J. E., Pedersen, H. B., Ronald, A. R., Bonin, P., and Tronca, E. L. (1968) F. Amer. med. Ass., 203, 909

FlukeR, J. L., and Hewitt, A. B. (1970) Brit. F. vener. Dis., 46, 454

Hantschke, D., Strauss, P., Linzenmeier, G., Gahlen, D., and HeLleR, W. (1973) Ibid., 49, 62 
Hooton, W. F., and Nicol, C. S. (1967) Postgrad. med. f., 43, Suppl. (May), p. 68

Izzat, N. N., Smith, E. B., and Knox, J. M. (1972) Brit. F. vener. Dis. 48, 342

Johnson, D. W., Kvale, P. A., Afable, V. A., Stewart, S. D., Halverson, C. W., and Holmes, K. K. (1970) New Engl. F. Med., 283, 1

Pedersen, A. H. B., Wiesner, P. J., Holmes, K. K., Johnson, C. J., and Turck, M. (1972) F. Amer. med. Ass., 220, 205

Phillips, I., Rimmer, D., Ridley, M., LynN, R., and WARREN, C. (1970) Lancet, 1, 263

SCHROETER, A. L., and REYNolds, G. (1972) f. infect. Dis., 125, 499

Siboulet, A. (1972) Postgrad. med. F., 48, Suppl. (Jan.), p. 65
Waitz, J. A., and Weinstein, M. J. (1969) f. infect. Dis., 119,355

Wilkinson, A. E., Race, J. W., and Curtis, F. R. (1967)

Postgrad. med. F., 43, Suppl. (May), p. 65

La Gentamicine dans le traitement de la gonococcie féminine

SOMMAIRF

La Gentamicine, à la dose de $240 \mathrm{mg}$ intra-musculaire, a servi au traitement de 55 femmes présentant une gonococcie cervicale. Sur les 48 qui revinrent pour une surveillance appropriée, 44 furent considérées comme guéries. Chez les 4 malades?ayant présenté une reprise, 2 furent presque certainement réinfectées. Ainsi, le taux de succès fut au moins de 92 pour cent. 